\title{
Author self-archiving policy
}

\section{Last updated December 2016}

Many funders now mandate that their sponsored research must be deposited in an institutional repository. For a list of funders and their open access requirements, see http://www.sherpa.ac.uk/juliet/.

In order to allow authors to comply with these mandates, the IET offers a comprehensive author selfarchiving policy. With no embargo period, authors are permitted to deposit the complimentary copy of their manuscript (reviewed, revised and typeset, but not the final published PDF) in their institutional repository or in repositories designated by their funding body, provided they refer to the published IET version. For full details of the policy and any relevant wordings, see below.

These options will allow our authors to comply with the mandates of a number of funders/research bodies, including, but not limited to EPSRC, RCUK, NIH, Wellcome Trust, Horizon 2020, HEFCE, and NERC. If you are unsure if the IET will help you to comply with your funder's mandates, please contact us at journals@theiet.org.

The following outlines the full IET author self-archiving policy:

\section{Preprints}

On submission of their manuscript, authors may deposit the submitted version in their personal, institutional, or online pre-print repository (for example, arXiv). The first page of the manuscript must clearly display the following wording: "This paper is a preprint of a paper submitted to [journal]. If accepted, the copy of record will be available at the IET Digital Library". On acceptance and where copyright has been transferred to the IET, this must be changed to: "This paper is a preprint of a paper accepted by [journal] and is subject to Institution of Engineering and Technology Copyright. When the final version is published, the copy of record will be available at the IET Digital Library". If the paper is rejected, authors must remove all mention of the journal.

\section{Postprints}

After acceptance and where copyright has been transferred to the IET, authors should remove the originally submitted pre-print and may immediately deposit the complimentary copy of their manuscript (reviewed, revised and typeset, but not the final published PDF). The following wording must clearly appear on the front page of the paper: "This paper is a postprint of a paper submitted to and accepted for publication in [journal] and is subject to Institution of Engineering and Technology Copyright. The copy of record is available at the IET Digital Library".

\section{Creative Commons licences}

For articles published under a Creative Commons licence all versions (including the final published version) may be deposited. The published source must be acknowledged, the DOI cited and a link given to the version on the IET Digital Library.

ResearchGate: The IET classes ResearchGate as a social media site and as such authors are able to upload the complimentary copy of their manuscript (reviewed, revised and typeset, but not the published PDF) with the appropriate wording.

Any questions should be addressed to the editorial office (journals@theiet.org). 